\title{
A soberania patriarcal : o sistema de justiça criminal no tratamento da violência sexual contra a mulher
}

Vera Regina Pereira de Andrade ${ }^{1}$

Resumo:

O texto aborda, sob o marco teórico da Criminologia desenvolvida com base no paradigma do controle social, particularmente a Criminologia crítica e feminista, o funcionamento do sistema de justiça criminal relativamente à violência sexual contra a mulher, apontando para a soberania do patriarcado e a duplicação da violência que ele arrasta consigo, e para a necessidade de inclusão e co-responsabilizacão de todos nós, enquanto co-partícipes institucionais ou simbólicos do controle social e penal, na ultrapassagem da mecânica da violência, concebida em sua dimensão estrutural, institucional e intersubjetiva.

Palavras-chave: Sistema de justiça criminal - controle social e penal -Criminologia violência contra a mulher -gênero-vitima

“Temos direito a reivindicar a igualdade
quando a desigualdade nos inferioriza;
temos direito a reivindicar a diferença
quando a igualdade nos descaracteriza.”

(Boaventura de Sousa Santos)

\footnotetext{
${ }^{1}$ Mestre e Doutora em Direito pela Universidade Federal de Santa Catarina (UFSC). Pós Doutoranda em Direito Penal e Criminologia pela Universidade de Buenos Aires. Professora nos Cursos de Graduação e Pós-Graduação em Direito da UFSC. Pesquisadora do CNPq e da Fundação Cassamarca - Treviso ( Itália)
} 


\section{1) O lugar da fala : uma palavra sobre a dor, o saber e o (s) sujeito(s). O continuum criminológico e o argumento}

Despindo-me das pseudo assepsias do cientificismo secular, devo iniciar dizendo que o universo da violência é, antes de mais nada, um universo de dor, e que se enfrentá-lo como objeto teórico e de reflexão implica necessariamente um esforço de suspensão da dor, colocá-la em suspenso não implica, em momento algum, perdê-la de vista ou divorciar-se dela, porque é a solidariedade para com a dor e o propósito de contribuir para superá-la que motiva nossa tentativa de resgatar, para o problema, a voz dos saberes emancipatórios. ${ }^{2}$

E um campo do saber ( teórico e empírico) no qual identifico esta potencialidade emancipatória e embaso minha argumentação é o proveniente da Criminologia desenvolvida com base no paradigma do controle ou reação social ( desde a década de 60 século XX) e, mais espeficamente, a Criminologia crítica e a Criminologia feminista , pois, através deste continuum o sistema de justiça criminal ${ }^{3}$ - este sujeito monumental - não apenas veio a constituir-se no objeto criminológico central do nosso tempo, mas veio a sê-lo inclusive, sob o influxo do feminismo, no tratamento que imprime à mulher.

Podemos demarcar, pois, neste continuum, três grandes momentos históricos e epistemológicos:

1)na década de 60, consolida-se a passagem de uma Criminologia do crime e do criminoso, ou seja, da violência individual (de corte positivista e clínico) para uma Criminologia do sistema de justiça criminal e da violência institucional (de corte construtivista- interacionista), amadurecida através de dois saltos qualitativos, a saber

2)a partir da década de 70, o desenvolvimento materialista desta Criminologia marca a passagem para as chamadas Criminologia radical, Nova Criminologia e Criminologia crítica, no âmbito das quais o sistema de justiça criminal receberá uma interpretação macrossociológica no marco das categorias capitalismo e classes sociais(Criminologia da violência estrutural)

3) e a partir da década de 80 , o desenvolvimento feminista da Criminologia crítica

\footnotetext{
2. Eis que assumo esta como uma discussão paradigmática, cujo enfoque depende dos paradigmas eleitos, ou seja, do lugar de onde (e do que) se fala.

3 . Doravante também designado por SJC.
} 
marca a passagem para a Criminologia de correspondente nomenclatura, no âmbito da qual o sistema de justica criminal receberá também uma interpretação macrossociológica no marco das categorias patriarcado e gênero ${ }^{4}$, e a indagação sobre como o sistema de justiça criminal trata a mulher ( a mulher como vítima e uma Vitimologia crítica) assume aqui um lugar central.

Fundamental, portanto, invocar a importância do feminismo como outro sujeito coletivo monumental que, fazendo a mediação entre a história de um saber masculino onipresente e a história de um sujeito ausente - o feminino e sua dor- e ressignificando a relação entre ambas, aparece como fonte de um novo poder e de um novo saber de gênero, cujo impacto (científico e político) foi profundo no campo da Criminologia, com seu universo até então completamente prisioneiro do androcentrismo : seja pelo objeto do saber (o crime e os criminosos), seja pelos sujeitos produtores do saber ( os criminólogos)ou pelo próprio saber . “ O Homem criminoso” ( 1871-1876) título da histórica obra do médico italiano César Lombroso, é emblemática a respeito, muito embora o próprio Lombroso, na continuidade, já abordasse a criminalidade das fêmeas. A Criminologia, portanto, nascida oficialmente no século XIX como a ciência da criminalidade, do crime e do criminoso, transformou-se e está a se transformar, cada vez mais, numa teoria crítica e sociológica do sistema de justiça criminal ( ciência social) se ocupando , fundamentalmente, da análise de sua complexa fenomenologia e funcionalidade nas sociedades capitalistas e patriarcais.

Não estamos, todavia, perante edifícios acabados, mas construções abertas, processuais. Penso, inclusive, que uma das mais fortes interpelações criminológicas do presente é precisamente o desenvolvimento unificado das perspectivas " crítica " $\mathrm{e}$ " feminista", na era da globalização, eis que uma tal bipartição epistemológica não pode ser senão provisória.

Da solidez dos seus alicerces já emergiram, contudo, resultados criminológicos irreversíveis, de que vou me ocupar, exercitando precisamente o aludido esforço unificador.

\footnotetext{
4 Para além do dado biológico que define o sexo ( cada nascimento requer um registro sexual, homemmulher), o gênero será concebido como o sexo socialmente construído ( a dicotomia femininomasculino).
} 
Foi com base neste saber que desenvolvi, sob o patrocínio do CNPQ, uma pesquisa intitulada "Sistema da Justiça Penal e violência sexual contra as mulheres : análise de julgamento de crimes sexuais em Florianópolis, na década de oitenta."5

Esta pesquisa parte da análise teórica e empírica do funcionamento do SJC relativamente à violência sexual contra a mulher para sustentar e concluir o seguinte:

1) num sentido fraco, o SJC é ineficaz para a proteção das mulheres contra a violência porque, entre outros argumentos, não previne novas violências, não escuta os distintos interesses das vítimas, não contribui para a compreensão da própria violência sexual e a gestão do conflito e, muito menos, para a transformação das relações de gênero.

O sistema não apenas é estruturalmente incapaz de oferecer alguma proteção à mulher, como a única resposta que está capacitado a acionar - o castigo - é desigualmente distribuído e não cumpre as funções preventivas ( intimidatória e reabilitadora) que se lhe atribui. Nesta crítica se sintetizam o que denomino de incapacidades protetora, preventiva e resolutória do SJC.

2) num sentido forte, o SJC (salvo situações contingentes e excepcionais) não apenas é um meio ineficaz para a proteção das mulheres contra a violência (particularmente da violência sexual, que é o tema da pesquisa), como também duplica a violência exercida contra elas e as divide, sendo uma estratégia excludente que afeta a própria unidade ( já complexa) do movimento feminista.

Isto porque se trata de um subsistema de controle social, seletivo e desigual, tanto de homens como de mulheres e porque é, ele próprio, um sistema de violência institucional, que exerce seu poder e seu impacto também sobre as vítimas.

E, ao incidir sobre a vítima mulher a sua complexa fenomenologia de controle social, que representa, por sua vez, a culminação de um processo de controle que certamente inicia na família, o SJC duplica, ao invés de proteger, a vitimação feminina, pois além da violência sexual representada por diversas condutas masculinas ( estupro, atentado violento ao pudor, etc.), a mulher torna-se vítima da violência institucional

5. A pesquisa foi desenvolvida no período de agosto de 1996 a agosto de 1997. A respeito ver ANDRADE, Vera Regina Pereira de. Sistema penal máximo x Cidadania mínima. Livraria do Advogado: Porto Alegre, 2003. p. 81-124. 
plurifacetada do sistema, que expressa e reproduz, por sua vez, dois grandes tipos de violência estrutural da sociedade: a violência das relações sociais capitalistas (a desigualdade de classe) e a violência das relações sociais patriarcais (traduzidas na desigualdade de gênero) recriando os estereótipos inerentes a estas duas formas de desigualdade, o que é particularmente visível no campo da violência sexual.

A passagem da vítima mulher ao longo do controle social formal acionado pelo sistema de justiça criminal implica, nesta perspectiva, vivenciar toda uma cultura da discriminação, da humilhação e da estereotipia. Pois, e este aspecto é fundamental, não há uma ruptura entre relações familiares (Pai, padastro, marido), trabalhistas ou profissionais (chefe) e relações sociais em geral (vizinhos, amigos, estranhos, processos de comunicação social) que violentam e discriminam a mulher, e o sistema penal que a protegeria contra este domínio e opressão, mas um continuum e uma interação entre o controle social informal exercido pelos primeiros ( particularmente a família) e o controle formal exercido pelo segundo.

\section{2)O que sabemos sobre a identidade do sistema de justiça criminal: quem é o sistema e o que promete?}

Para desenvolver o argumento, inicio por indagar: quem é o sistema de justiça criminal? E indago quem, precisamente porque se trata de um sujeito, e de um sujeito monumental ( em abrangência e poder).

\section{1) Dimensão normativa e institucional -instrumental: o sistema é o Outro}

A primeira dimensão e imagem do SJC é a da Lei ${ }^{6} \mathrm{e}$ das instituições formais de controle, ou seja, a sua dimensão stricto sensu, sem dúvida a mais visível : Polícia, Ministério Público, Justiça, Sistema Penitenciário, com sua constelação prisional e manicomial : decisões policiais, ministeriais, judiciais, penitenciárias ${ }^{7}$. Aqui o Estado se faz onipresente em nível Legislativo, Executivo e Judiciário, e o sistema é monumentalmente percebido como sendo o Outro.

\section{2)Dimensão integrativa do controle social informal: O Outro não está Só}

\footnotetext{
6 . Lei(s), Penais, Processuais Penais, Penitenciárias, Constituição, Declarações Internacionais.

7. E ainda, Ministérios e/ou Secretarias da Justiça ,da Segurança pública, do Interior, e outros: decisões governamentais.
} 
Enquanto mecanismo de controle ${ }^{8}$, o SJC, entretanto, não está só, mas inserido na mecânica global de controle social, de tal modo que não se reduz ao complexo estático da normatividade nem da institucionalidade, mas é concebido como um processo articulado e dinâmico de criminalização ao qual concorrem não apenas as instituições do controle formal, mas o conjunto dos mecanismos do controle social informal, a saber, Família, Escola (desde a pré-escola até a Pós-Graduação, especialmente as Escolas formadoras dos operadores do SJC), mídia falada, escrita ( jornais, literatura, romances, histórias em quadrinho) e informática, moral, religião, mercado de trabalho, etc.

Existe, portanto, um macrossistema penal formal, composto pelas instituições oficiais de controle, circundado pelas instituições informais de controle, e nós integramos e participamos da mecânica de controle , seja como operadores formais ou equivalentes, seja como senso comum ou opinião pública.

Chega-se, por esta via, à dimensão ideológica do SJC.

\section{3)Dimensão ideológica-simbólica: o sistema somos todos Nós}

Com efeito, uma dimensão muito mais invisível e difusa ( lato sensu) do sistema é a dimensão ideológica ou simbólica, representada tanto pelo saber oficial ( as Ciências criminais) quanto pelos operadores do sistema e pelo público, enquanto senso comum punitivo ( ideologia penal dominante). Esta capilaridade não deve obscurecer, entretanto, a sua onipresença, tanto ou mais expressiva que a do Estado, e que obriga à percepção de que o sistema somos, informalmente, todos nós: em cada sujeito se desenha e opera, desde a infância, um microssistema de controle e um microssistema criminal ( simbólico) que o reproduz, cotidianamente.

Referir a dimensão simbólica do sistema implica referir os discursos (as representações e as imagens) das Ciências criminais que, conjuntamente com o discurso da lei, tecem o

\footnotetext{
${ }^{8}$. Por controle social designa-se, em sentido lato, as formas com que a sociedade responde, informal ou formalmente, difusa ou institucionalmente, a comportamentos e a pessoas que contempla como desviantes, problemáticos, ameaçantes ou indesejáveis, de uma forma ou de otra e, nesta reação, demarca (seleciona, classifica, estigmatiza) a próprio desvio e a criminalidade como uma forma específica dele. Daí a distinção entre controle social informal ou difuso e controle social formal ou institucionalizado. A unidade funcional do controle é dada por um princípio binário e maniqueísta de seleção; a função do controle social, informal e formal, é selecionar entre os bons e os maus os incluídos e os excluídos ; quem fica dentro, quem fica fora do universo em questão, sobre os quais recai o peso da estigmatização.
} 
fio de sua (auto)legitimação oficial, pois é do processo de reprodução ideológica do sistema do que aqui se trata.

Com efeito, é precisamente a Lei e o saber ( Ciências Criminais), dotados da ideologia capitalista e patriarcal, que dotam o sistema de uma discursividade que justifica e legitima sua existência ( ideologias legitimadoras), co-constituindo o senso comum punitivo reproduzido, por sua vez, pelo conjunto dos mecanismos de controle social, com ênfase, contemporaneamente, para a mídia.

É notável o esforço histórico das Ciências Criminais na tentativa de fazer a assepsia entre o sistema de justiça criminal e o sistema social e o convencimento jurídico-penal e público de um como se; como se o SJC funcionasse como se declara.

São, assim, funções oficialmente declaradas ou promessas legitimadoras do SJC: proteção de bens jurídicos que interessam igualmente a todos os cidadãos ( o bem) através do combate eficaz à criminalidade ( o $m a l$ ), a ser instrumentalizado através das funções da pena: uma combinatória de retribuição ou castigo com prevenção geral ( intimidação erga omnes pela ameaça da pena cominada em abstrato na lei penal) e especial (reabilitação in persona através da execução penal) a ser aplicada dentro dos mais rigorosos princípios penais e processuais penais liberais ( legalidade, igualdade jurídica, devido processo, etc)

Estamos perante uma ideologia extremamente sedutora, também para as mulheres, e com um fortíssimo apelo legitimador ( da protecão, da evitacão, da solucão)

como se à edição de cada lei penal, sentença, ou cumprimenro de pena, fosse mecanicamente sendo cumprido o pacto mudo que opera o traslado da barbárie ao paraíso. Por isto mesmo esta ideologia legitimadora se mantém constante até nossos dias e consubstancia o que Alessandro Baratta denomina o "mito do Direito Penal igualitário". 9

\section{3)O que sabemos sobre a funcionalidade do sistema de justiça criminal}

\section{1) Das funções declaradas às funções reais e à eficácia invertida}

Passando à análise da funcionalidade do SJC, o ponto de inflexão fundamental a demarcar é a contradição entre funções declaradas e funções latentes, pois sabemos, criminologicamente, que há não apenas um profundo déficit histórico de cumprimento

\footnotetext{
9 . BARATTA, Alessandro. Criminologia crítica e política penal alternativa.Tradução por J. Sérgio Fragoso. Revista de Direito Penal, Rio de Janeiro, n. 23, p. 7-21, jul/dez. 1978. p.9-10
} 
das promessas oficialmente declaradas pelo seu discurso oficial (do qual resulta sua grave crise de legitimidade) como o cumprimento de funções latentes inversas às declaradas. Razão pela qual afirmei em outro lugar que o SJC caracteriza-se por uma eficácia instrumental invertida à qual uma eficácia simbólica (legitimadora) confere sustentação; ou seja, enquanto suas funções declaradas ou promessas apresentam uma eficácia meramente simbólica ( reprodução ideológica do sistema) porque não são e não podem ser cumpridas, ele cumpre, latentemente, outras funções reais, não apenas diversas, mas inversas às socialmente úteis declaradas por seu discurso oficial, que incidem negativamente na existência dos sujeitos e da sociedade.

Mas é precisamente o funcionamento ideológico do sistema - a circulação da ideologia penal dominante entre os operadores do sistema e no senso comum ou opinião pública que perpetua o ilusionismo, justificando socialmente a importância de sua existência e ocultando sua reais e invertidas funções. Daí apresentar uma eficácia simbólica sustentadora da eficácia instrumental invertida

A eficácia invertida significa, então, que a função latente e real do sistema não é combater ( reduzir e eliminar) a criminalidade, protegendo bens jurídicos universais e gerando segurança pública e jurídica mas, ao invés, construí-la seletiva e estigmatizantemente e neste proceso reproduzir, material e ideologicamente, as desigualdades e assimetrias sociais (de classe, gênero, raça ).

Neste sentido não reage contra uma criminalidade que existe ontologicamente na sociedade independentemente da sua intervenção, mas é a própria intervenção do sistema (autêntico exercício de poder, controle e domínio) que, ao reagir, constrói, coconstitui o universo da criminalidade ( daí processo de criminalização) mediante: a) a definição legal de crimes pelo Legislativo, que atribui à conduta o caráter criminal, definindo-a ( e, com ela, o bem jurídico a ser protegido) e apenando-a qualitativa e quantitativamente ( criminalização primária) e b) a seleção das pessoas que serão etiquetadas, num continuum pela Polícia-Ministério Público e Justiça ( criminalização secundária) e c)estigmatizadas ,especialmente na prisão, como criminosos entre todos aqueles que praticam tais condutas ( criminalização terceária). ${ }^{10}$

\footnotetext{
10 . Desenvolvidamente, cf ANDRADE, Vera Regina Pereira de. A Ilusão de Segurança jurídica $2^{\mathrm{a}}$. edição.Porto Alegre: Livraria do Advogado, 2003 e Vera Regina Pereira de Sistema Penal máximo x cidadania mínima: códigos da violência na era da globalização. Porto Alegre: Livraria do Advogado, 2003 .
} 
Mas, precisamente porque o sistema não está só, para compreender sua funcionalidade é necessário apreendê-lo como um subsistema dentro de um sistema de controle e seleção de maior amplitude, pois o SJC penal não realiza o processo de criminalização/vitimização e estigmatização à margem ou inclusive contra os processos gerais de etiquetamento que tem lugar no seio do controle social informal, como a família e a escola (por exemplo, a filha estigmatizada como " ovelha negra” ou " menina fácil" , o aluno como " difícil" pelo professor etc.) e o mercado de trabalho, entre outros.

Toda a mecânica de controle ( enraizada nas estruturas sociais) é constitutiva/reprodutora das assimetrias de que, afinal, se engendram e alimentam os estereótipos ${ }^{11}$, os preconceitos e as discriminações, sacralizando hieraquias. E nós interagimos cotidianamente na mecânica (inseridos que estamos em relações de poder nem sempre percebidas, sendo sujeitos constituídos e constituintes, controlados e controladores), particularmente na dimensão simbólica da construção social da criminalidade/vitimação, representada por nosso microssistema ideológico que procede a microseleções cotidianas, ao associar, estereotipadamente, criminosos com homens pobres, desempregados de rua com perigosos, estupradores com homens de lascívia desenfreada, vítimas com mulheres frágeis, etc, e reproduz o SJC.

\section{2) A seletividade estigmatizante: a seleção de criminosos e vítimas dentre todos} nós

A seletividade é, portanto, a função real e a lógica estrutural de funcionamento do SJC, comum às sociedades capitalistas/patriarcais. E nada simboliza melhor a seletividade do que a clientela da prisão ao nos revelar que a construção ( instrumental

${ }^{11}$.Os estereótipos, designados por Karl-Dieter Opp e A. Peukert por "Handlungsleitenden Theorien" (teorias diretivas da ação) e por W.Lippman (considerado o primeiro a refletir de forma sistemática sobre eles) por pictures in our minds (imagens em nossa mente) são construções mentais, parcialmente inconscientes que, nas representações coletivas ou individuais ligam determinados fenômenos entre si e orientam as pessoas na sua atividade quotidiana, influenciando também a conduta dos juízes. A respeito ver DIAS, Jorge de Figueiredo, ANDRADE, Manuel da Costa. Criminologia:o homem delinqüente e a sociedade criminógena. Coimbra: Coimbra, 1984. p.347-8 (e nota 181), p.388-9 e 553; SCHUR, Edwin M. Labeling Deviant Behavior. Its Sociological Implications. New York: Harper \& Row, 1971.p. 40 
e simbólica ) da criminalidade - a criminalização - incide seletiva e estigmatizantemente sobre a pobreza e a exclusão social, majoritariamente masculina, e apenas residualmente ( embora de forma crescente) feminina.$^{12}$

A seletividade pode então ser formulada nos seguintes termos: todas as pessoas, de todos os estratos sociais, faixas etárias, etnias e gênero, ou seja, todos nós ( e não uma minoria perigosa da sociedade) praticamos, freqüentemente, fatos definidos como crimes, contravenções ou infrações administrativas e somos, por outro lado, vítimas destas práticas ( o que muda é a especificidade das condutas). Assim, tanto a criminalidade, quanto a vitimação, são majoritárias e ubícuas ( todos nós somos criminosos e vítimas), percepção heurística para um senso comum acostumado a olhar o problema criminal como um problema do(s) Outro(s) e a manter com ele uma reçaçãp de exterioridade, e, portanto de imunização. ${ }^{13}$ Ora, se a conduta criminal é majoritária e ubíqua e a clientela do sistema penal é composta, regularmente, em todos os lugares do mundo, por homens adultos jovens pertencentes aos mais baixos estratos sociais e, em grande medida, não brancos, isto significa que impunidade e criminalização ( e também a vitimação) são orientados pela seleção desigual de pessoas de acordo com uma fortíssima estereotipia presente no senso comum e dos operadores do controle penal, e não pela incriminação igualitária de condutas , como programa o discurso jurídicopenal.

Para além, contudo, da ênfase criminológica crítica na construção seletiva da criminalidade, na criminalização seletiva, ou seja, na distribuição desigual do status negativo de criminoso, é necessário enfatizar, na esteira da Criminologia feminista, a construção seletiva da vitimação ( que não aparece nas estatísticas), eis que o sistema também distribui desigualmente a vitimação e o status de vítima; até porque autorvítima é um par que mantém, na lógica adversarial do sistema de justiça , uma relação

\footnotetext{
12. Tomando-se por referente os Censos Penitenciários Brasileiros realizados pelo Conselho Nacional de Política Criminal e Penitenciária do Ministério de Justiça a partir de 1995, podemos constatar que no Brasil há uma aproximação entre os dados da criminalização da pobreza ( em torno de 95\%) e os dados da criminalização masculina (em torno de $96 \%$, contra aproximadamente $4 \%$ de criminalização feminina)

13 . Precisamente uma das conseqüências fundamentais dos paradigmas criminológicos aqui utilizados é a de nos conduzir a uma percepção diferenciada da criminalidade, da vitimação e do sistema de justiça criminal que, permitindo suplantar a relação de exterioridade com que nos colocamos perante ambos, reenvia a uma relação de inclusão e, consequientemente, de responsabilização. Todos nós somos criminosos, vítimas, sistemas criminais e, portanto, o problema também é nosso.
} 
visceral: reconhecer autoria implica, tácita ou expressamente, reconhecer vitimação . A impunidade é a contra-face do processo.

A vitimação, assim como a criminalidade, também é uma possibilidade majoritária mas desigualmente distribuída de acordo com estereótipos de vítimas que operam no senso comum e jurídico Pois, com efeito, "a intervenção estereotipada do sistema penal age tanto sobre a 'vítima', como sobre o 'delinqüiente'. Todos são tratados da mesma maneira."14

Nesta esteira, deve-se apreender tanto a vulnerabilidade à criminalização quanto à vulnerabilidade à vitimação, como veremos a seguir.

Considerando, enfim, que o SJC está estruturalmente dedicado "a administrar uma reduzidíssima porcentagem das infrações, seguramente inferior a 10\%."15 conclui-se não apenas que " os processos de imunizacão constituem a interface negativa dos processos de criminalizacao", ${ }^{16}$ mas que imunidade ${ }^{17}$ e impunidade constituem a regra de funcionamento do sistema de justiça criminal e não sua disfunção. ${ }^{18}$

\section{4) O patriarcado e o capitalismo como matrizes históricas do sistema de justiça criminal: o sentido das seleções}

Evidentemente que um tal funcionamento interno do SJC e do controle social somente adquire sua significação plena quando reconduzido ao sistema social (à dimensão macrossociológica) e inserido nas estruturas profundas em ação que o condicionam, a saber, o capitalismo e o patriarcado, que ele expressa e contribui a reproduzir e relegitimar, aparecendo, desde sua gênese, como um controle seletivo classista e sexista ${ }^{19}$ ( ademais de racista), no qual a estrutura e o simbolismo de gênero operam desde as

\footnotetext{
14 . HULSMAN, Louk; BERNAT DE CELIS, Jacqueline. Penas Perdidas: o sistema penal em questão. Tradução por Maria Lúcia Karam. Rio de Janeiro: Luam. 1993. p.83.

15 . BARATTA, Alessandro. Direitos Humanos: entre a violência e a violência penal. Fascículos de Ciências Penais, Porto Alegre, n. 2, abr./maio/jun 1993, p.49.

${ }^{16}$. BARATTA, Alessandro. O paradigma do gênero: da questão criminal à questão humana. In CAMPOS, Carmen Hein de. (Org.). Ciminologia e Feminismo. Porto Alegre: Sulina, 1999, p.48

17 . Imune diz-se da conduta criminal que fica completamente na cifra oculta, ou seja, ignorada de qualquer agência do sistema. Impune é a conduta criminal que chega ao conhecimento do sistema, mas, em alguma das agências, é interrompido o processo de criminalizaçao, não sendo objeto de punição.

18 . HULSMAN, Louk; BERNAT DE CELIS, Jacqueline. Penas Perdidas: o sistema penal em questão. Tradução por Maria Lúcia Karam. Rio de Janeiro: Luam. 1993.p.65

19 . Ou, em outras palavras, sendo as nossas sociedades, contemporaneamente, capitalistas e patriarcais, a funcionalidade do sistema penal guarda com estas matrizes históricas uma conexão funcional, ao tempo que as desvela, operando " como um caledoscópio no âmbito do qual o funcionamento de certos mecanismos é esclarecido."
} 
entranhas de sua estrutura conceitual, de seu saber legitimador, de suas instituições, a começar pela linguagem ${ }^{20}$ : eis o sentido da seletividade.

Ora, nisto o SJC replica a lógica e a função real de todo mecanismo de controle social, a saber, em nível micro, ser um exercício de poder e de produção de subjetividades (a seleção binária entre o bem e o mal, o masculino e o feminino) e, em nível macro, ser um exercício de poder (de homens e mulheres) reprodutor de estruturas, instituições e simbolismos. E o SJC ocupa um importantíssimo lugar na manutenção do status quo social.

Nesta esteira a constatação fundamental de Alessandro Baratta ${ }^{21}$, segundo a qual “ Para compreender o mecanismo geral de reprodução do status quo da nossa sociedade, contemporaneamente patriarcal e capitalista, faz-se necessário ter presente não apenas a importância estrutural da separacão entre esfera pública e privada, mas também, da complementariedade dos mecanismos de controle próprios dos dois círculos. Em um corpo social como o nosso, a divisão entre público e privado, formal informal, constitui um instrumento material e ideológico fundamental para o funcionamento de uma economia geral do poder, na qual todas as várias relações de domínio encontram o seu alimento específico e, ao mesmo tempo, se entrelaçam e sustentam. “

\section{5)O que sabemos sobre a funcionalidade de gênero: o androcentrismo do sistema}

\section{de justiça criminal}

\section{1) A construção social do gênero no patriarcado: espaços, papéis e estereótipos}

Necessário, portanto, olhar doravante para o androcentrismo do SJC e sua funcionalidade de gênero, e para tanto é necessário uma breve incursão sobre a construção social do gênero (a dicotomia masculino-feminino)no patriarcado; construção que, como é sabido, encontra-se em descontrução, mas, como parece ser

BERGALLI, Roberto y BODELÓN, Encarna. La cuestión de las mujeres y el derecho penal simbólico. Anuário de Filosofia del derecho LX. Madrid, Ministério da Justiça, 1992, p.54.

${ }^{20}$.O universalismo ( abstrato e generalizante) e a objetividade, sendo atributos fundantes do modelo androcêntrico de sociedade, serão também do modelo androcêntrico de ciência e de sistema de justiça criminal, cuja contradição básica pode ser flagrada desde a linguagem, estruturalmente masculina e estigmatizante, com que afirma seus ideais protetores igualitários.

${ }^{21}$. BARATTA, Alessandro. O paradigma do gênero: da questão criminal à questão humana. In CAMPOS, Carmen Hein de. (Org.). Ciminologia e Feminismo. Porto Alegre: Sulina, 1999, p.48. 
menos evidente, continua operando, sobretudo no SJC. Isto implica falar em espaços (divisão entre público e privado com correspondente divisão social do trabalho) papéis (atribuição de papéis diferenciados aos sexos, sobre ou subordinado, nas esferas da produção, da reprodução e da política)e estereótipos.

A esfera pública, configurada como a esfera da produção material, centralizando as relações de propriedade, o trabalho produtivo ( e a moral do trabalho), tem seu protagonismo reservado ao Homem enquanto sujeito produtivo, mas não qualuer Homem. A estereotipia correspondente para o desempenho deste papel (trabalhador de rua) no homem racional/ativo/forte/potente/guerreiro/viril/publico/possuidor. ${ }^{22}$

A esfera privada, configurada, a sua vez, como a esfera da reprodução natural, e aparecendo como o lugar das relações familiares ( casamento, sexualidade reprodutora, filiação e trabalho doméstico) tem seu protagonismo reservado à mulher, através do aprisionamento de sua sexualidade na função reprodutora e de seu trabalho no cuidado do lar e dos filhos. É precisamente este o eixo da dominação patriarcal.

Os atributos necessários ao desempenho deste papel subordinado ou inferiorizado de esposa, mãe e trabalhadora do lar(doméstico), ${ }^{23}$ são exatamente bipolares em relação ao seu outro. A mulher é então construida femininamente como uma criatura emocional/subjetiva/passiva/frágil/impotente/pacífica/recatada/doméstica/possuída.

Em síntese, espaço público-papéis patrimoniais - estereótipos do pólo da atividade: ao patrimônio, o cuidado dos bens.

Espaço privado-papéis matrimoniais - estereótipos do pólo da passividade : ao matrimônio o cuidado do lar.

Estamos perante o simbolismo de gênero com sua poderosa estereotipia e carga estigmatizante. Este simbolismo (enraizado nas estruturas) que homens e mulheres, no entanto, reproduzem, apresenta a polaridade de valores culturais e históricos como se fossem diferenças naturais ( biologicamente determinadas) e as pessoas do sexo

\footnotetext{
22 .abstração, objetividade, orientação segundo princípios (os mesmos que qualificam a epistemologia positivista).

${ }^{23}$. Merece observação e reparos a desqualificação ( ainda que contextualmente justificada), que o feminismo de primeira geração procedeu, aos papéis femininos na esfera privada, sejam de esposa, mãe ou trabalhadora do lar. Sem dúvida que todos estes papéis, fora da condição de subalternidade do domínio patriarcal e no seu exercício com autonomia, são majestosos e importantes para o crescimento existencial da mulher, particularmente o de Mãe, experiência fecunda para a ressignificação da vida. Esta visão positiva tem vindo a ser, inclusive, a asssumida pelos feminismos subseqüentes.
} 
feminino como membros de um gênero subordinado, na medida em que determinadas qualidades, bem como o acesso a certos papéis e esferas ( da Política, da Economia e da Justiça, por exemplo ) são percebidos como naturalmente ligados a um sexo biológico e não ao outro. ${ }^{24}$

De tal maneira que a mulher é construída como (não) sujeito do gênero feminino.

\section{2) O masculino ativo e o feminino passivo: o cara e a coisa, o criminoso $e$ a vítima}

Existe uma expressão na nossa cultura que é cotidianamente reproduzida e que emblematiza, magistralmente, a hiperatividade do sujeito masculino ou, como se queira, o machismo: esta expressão é o cara.

O cara é aquele sujeito onipresente e onisciente do nosso imaginário, plantonista de 24 horas, a quem recorremos para todos as demandas. Se eu vou contar uma história ativa, ela começa com um cara. O que estraga em casa, da telha ao vaso sanitário, tem que chamar um cara para consertar ; o que estraga ou se necessita na rua, do pneu furado às compras para carregar, tem que chamar um cara, e esse é um pedido masculino feito não apenas por mulheres, mas por mulheres e homens. Agora, o cara é também o vilão temido no mesmo plantão: se alguém tiver que entrar em nossa casa para roubar, se alguém tiver que colocar uma escada para subir na janela ou no telhado, será um cara. Se alguém tiver que nos assaltar na rua, será um cara. O cara é, a um só tempo, exaltado e temido, ação e reação.

Qual é o contraponto do cara?

O contraponto do cara é precisamente a coisa: aquilo que não age ou aquilo do que não nos lembramos: Me diz uma coisa? como é mesmo o nome daquela coisa? será que a dona coisa não vem? Ah, que coisa!

O SJC existe sobretudo para controlar a hiperatividade do cara e manter a coisa no seu lugar (passivo).

Na bipolaridade de gênero, não é difícil visualizar, no estereótipo do homem ativo e público acima referenciado as potencialidades do seu próprio outro, a saber, o antiherói socialmente construído como o criminoso, tanto mais perverso quanto temida a biografia de seu desvio; como não será difícil visualizar na mulher encerrada em seu espaço privado, o recato e os requisitos correspondentes à esterotipia da vítima.

\footnotetext{
${ }^{24}$.ALVES, José Eustáquio Diniz, CAVENAGUI, Suzana, Dominação masculina e discurso sexista.Informe ANDES, ano XI, n. 97- fev.2000, p.11.
} 
Aos homens poderosos e (im)produtivos o ônus da periculosidade e da criminalização; às mulheres fragilizadas ( como as crianças, os velhos, os homossexuais e outros excluídos do pacto da virilidade)o bônus? da vitimação.

O estereótipo de homem ativo no espaço público é o correspondente exato do estereótipo de criminoso perigoso no SJC. Mas não qualquer homem, o homem ativoimprodutivo. O poder colossal de que o patriarcado dota o homem e o gênero masculino, o capitalismo culmina, classistamente, por solapar.

O estereótipo da mulher passiva (objeto-coisificada) na construção social do gênero, divisão que a mantém no espaço privado (doméstico) é o correspondente exato do estereótipo da vítima no SJC. Mas não, como veremos, qualquer mulher. As mulheres não correspondem, em absoluto, ao estereótipo de criminoso (as), mas ao de vítima (s).

\section{3) O sistema de justiça criminal co-constituindo a construção social de gênero na construção social da criminalidade e da vitimação: integrando o controle social informal}

O SJC vai expressar e reproduzir a estrutura e o simbolismo de gênero, expressando e contribuindo a reproduzir o patriarcado - assim como o capitalismo. Dizer que é um sistema integrativo do controle social informal significa então que ele atua residualmente, no âmbito deste, mas neste funcionamento residual reforça o controle informal masculino e feminino, e os respectivos espaços, papéis e estereótipos a que devem se manter confinados.

Em realidade, o SJC é duplamente subsidiário ou residual ${ }^{25}$ relativamente ao controle social informal. Em primeiro lugar, funciona como um mecanismo público de controle dirigido primordialmente aos homens enquanto operadores de papéis masculinos na esfera pública da produção material e a pena publica é o instrumento deste controle.

Neste sentido, é integrativo do controle informal de mercado, reforçando o controle capitalista de classe. Com efeito, intervém de modo subsidiário para controlar o normal desenvolvimento das relações de produção e consumo - seleciona dentre os possuidores que não tiveram suficiente disciplina para o trabalho ou que tenham ficado à margem da economia formal e do mercado oficial de trabalho , como o demonstra a população carcerária ( déficit de instrução, posição precária no mercado de trabalho,

25 . BARATTA, Alessandro. O paradigma do gênero: da questão criminal à questão humana. In CAMPOS, Carmen Hein de. (Org.). Ciminologia e Feminismo. Porto Alegre: Sulina, 1999, p.18-80. 
toxicodependentes) ou, na era da globalização, excluídos de qualquer integração no mercado e, portanto, no reino do consumo.

Empiricamente, como vimos, são os homens que lotam as prisões, ao lado da incômoda presença de algumas mulheres, que nos Códigos sempre têm a seu favor a exculpante de um estado especial ( puerperal, mestrual, hormonal, emocional) e a sua espera os manicômios ( controle terapêutico) antes que as prisões. A loucura, os estados especiais, são os álibis de sua fragilidade: mulher só é perigosa e só corresponde ao estereótipo de perigo no trânsito! Do lado do sistema de justiça, nesse poderoso espaço publico, é novamente eles que historicamente vamos encontrar, como na masculina comunidade de criminólogos.

Neste sentido podemos dizer que o SJC é androcêntrico porque constitui um mecanismo masculino de controle para o controle de condutas masculinas, regra geral praticadas pelos homens, e só residualmente pelas mulheres.

Em segundo lugar, o mecanismo de controle dirigido às mulheres, enquanto operadoras de papeis femininos na esfera privada tem sido nuclearmente o controle informal materializado na Família ( Pais, padrastos, maridos, dele também co-participando a escola, a religião e a moral) e, paradoxalmente, a violência contra a mulher ( crianças, jovens e adultas), dos maus-tratos à violação e o homicídio, se reveste muitas vezes aqui de pena privada equivalente à pena pública.

É por esta dupla razão acima enunciada que indo em busca do sujeito feminino no catálogo masculino só residualmente vamos encontrá-lo. Tanto lendo o Código penal( criminalização primária) quanto olhando para as prisões ( (criminalização terceária) constatamos que o sistema só criminaliza a mulher residualmente e que, de fato, a trata como vítima.

O SJC funciona então como um mecanismo público integrativo do controle informal feminino, reforçando o controle patriarcal ( a estrutura e o simbolismo de gênero), ao criminalizar a mulher em algumas situações específicas ${ }^{26}$ e, soberanamente, ao

26 a)Criminalizando ( primariamente) condutas femininas : a mulher como autora de crimes contra a pessoa ( aborto, infanticídio, abandono de recém-nascido), crimes contra a família- casamento ( bigamia, adultério), crimes contra a família-filiação ( parto suposto, abandono de incapazes);

b) Criminalizando (secundariamente) as mulheres quando exercitam papéis socialmente masculinos ; ou seja, quando se comportam como homens, são violentas, usam armas;

c)Criminalizando (secundariamente) as mulheres quando praticam infrações em contextos de vida diferentes dos impostos aos papéis femininos ( não vivem em família ou as abandonam.)Aqui não apenas violam os tipos penais, mas a construção dos papéis de gênero como tais e o próprio " desvio socialmente esperado".

Seja como for, crimes próprios de mulheres ainda encontram acolhimento privilegiado no SJC : quando criminaliza, exculpa-as, de modo que a criminalização é simbólica, para reforçar os papéis de gênero, 
reconduzi-la ao lugar da vítima, ou seja, mantendo a coisa em seu lugar passivo.

6) O que sabemos sobre o sistema de justiça criminal no tratamento da violência (sexual) contra a mulher : como a mulher aparece no sistema?

\section{1) A mulher como vítima da violência sexual e o estupro : da lógica da seletividade à sublógica da honestidade e a seleção das vítimas}

E precisamente porque o núcleo do controle feminino no patriarcado é o controle da sexualidade ${ }^{27}$ ( implica preservação da virgindade e zelo pela reputação sexual) violência contra a mulher será recortada pelo SJC como violência sexual e a mulher aparece explicitamente como vítima da violência sexual ( no capítulo dos crimes contra os costumes), nuclearmente do estupro $^{28}$ ( cuja análise priorizarei aqui) e sua constelação ( atentados violento e fraudulento ao pudor, sedução, rapto, etc).

Na criminalização sexual o sistema criminal segue, talvez com mais contundência do

porque lugar de esposa e mãe é em casa. ( BARATTA, p.50-1).

Por outro lado, na medida em que as mulheres passam a exercer papéis masculinos na esfera publica elas tornam-se mais vulneráveis ao controle penal e é precisamente isto que esta a acontercer no mundo inteiro, elevando-se as taxas de criminalizacao feminina, pelas mesmas condutas que os homens são criminalizados, a saber, crimes patrimoniais e, nuclearmente, tráfico de drogas.

27 ORA, "o controle da sexualidade feminina, através de seu aprisionamento na função reprodutora,historicamente constitui, ao lado da centralidade do trabalho doméstico, um dos dois grandes eixos pelos quais se concretizam as relações específicas de dominação, estabelecidas no plano individual pela estruturação do patriarcado. Tal controle encontra na lei penal vigente largo campo de atuação, fazendo-se presente de forma visível na criminalizaçao de condutas como as definidas nos tipos de sedução, do rapto consensual, do adultério ou do aborto consentido (...)

Mas a presença da ideologia patriarcal vai mais além, estendendo-se por todo o tratamento dado às questões

ligadas à sexualidade e às relações familiares, do que talvez seja exemplo mais eloqüente a diferenciação de pena entre o estupro e o AVP ( 3 a 8 e 2 a 7) vigente até o advento da Lei 8.072/90. (KARAM, Maria Lúcia. Sistema penal e direitos da mulher. Revista Brasileira de ciências Criminais. São Paulo, Instituto Brasileiro de Ciências Criminais, n.9, p.147-163 jan.-mar.1995, p. 147).

No mesmo sentido, MURARO, Rose Marie. Textos da Fogueira. Brasília, Letraviva, 2000. p.74: “ A mulher jovem hoje liberta-se porque o controle da sexualidade e a reclusão do domínio privado formam os dois pilares da opressão feminina."

28. O estupro é definido no art. 213 do Código Penal brasileiro:

Constranger mulher à conjunção carnal, mediante violência ou grave ameaça.

Pena - reclusão, de 6 (seis) a 10 (dez ) anos.

$\mathrm{O}$ artigo $1^{\circ}$ da Lei $\mathrm{n}^{\circ}$ 8.072 de 25.07.1990 incluiu o estupro no rol de crimes hediondos aumentando as penas, anteriormente cominadas, de 3 a 8 anos, para 6 a 10 anos de reclusão (artigo $6^{\circ}$ ). $\mathrm{O}$ artigo $9^{\circ}$ determinou, por sua vez, que para as hipóteses de estupro na forma simples ( artigo 213) e qualificada ( artigo 213 c/c artigo 223 caput ) "as penas serão acrescidas de metade, respeitado o limite superior de trinta anos de reclusão, estando a vítima em qualquer das hipóteses referidas no art. 224 também do Código Penal." 
que em qualquer outra, a lógica da seletividade, acendendo seus holofotes sobre as pessoas (autor e vítima) envolvidas, antes que sobre o fato-crime cometido, de acordo com estereótipos de violentadores e vítimas. ${ }^{29}$

O diferencial é que há uma outra lógica específica acionada para a criminalização das condutas sexuais - a que denomino "lógica da honestidade" - que pode ser vista como uma sublógica da seletividade ${ }^{30}$ na medida em que se estabelece uma grande linha divisória entre as mulheres consideradas honestas (do ponto de vista da moral sexual dominante), que podem ser consideradas vítimas pelo sistema, e as mulheres desonestas ( das quais a prostituta é o modelo radicalizado), que o sistema abandona na medida em que não se adequam aos padrões de moralidade sexual impostos pelo patriarcado à mulher ; lógica que pode ser empiricamente comprovada ao longo do processo de criminalização desde a criminalização primária (definições legais dos tipos penais ou discurso da Lei) até os diferentes níveis da criminalização secundária (inquérito policial, processo penal ou discurso das sentenças e acórdãos) e a mediação do discurso jurídico-penal entre ambas.

Assim no título "Dos crimes contra os costumes" do Código Penal brasileiro ( cujo bem jurídico declarado penalmente protegido é a liberdade sexual) inteiramente atravessado pela ideologia patriarcal, diversos tipos penais requerem que a vítima seja "mulher honesta", como posse sexual mediante fraude (art. 214) atentado ao pudor mediante fraude (art. 215) sedução (art. 216) rapto consensual (art. 220) pré-selecionando a vitimação, já que estão excluídas, a priori, as mulheres desonestas e, em especial, as prostitutas.

E muito embora a definição legal do estupro (art. 213) prescinda desta exigência a lógica da honestidade é tão sedimentada que "os julgamentos de estupro, na prática, operam, sub-repticiamente, uma separação entre mulheres 'honestas' e mulheres 'não honestas'. Somente as primeiras podem ser consideradas vítimas de estupro, apesar do

\footnotetext{
29. Também aqui o sistema faz suas seleções binárias, existindo vítimas vítimas honestas e prostitutas ( expressão na clientela prisional), as quais, junto com o estuprador, simbolizam aquele ponto nevrálgico de junção entre o capitalismo e o patriarcado que a família patriarcal não pode suportar, prostitutas e estupradores, ao profanarem a monogamia sobre o interdito dos vários leitos, violam a um só tempo a regularidade do espaco privado e público - a unidade familiar e sucessória

30. Esta lógica pode ser claramente apreendida, entre outros, no filme de ficção Acusados, do diretor Jonathan Kaplan, que trata de um caso de estupro múltiplo, no qual uma jovem é vitima de três estupros numa só noite. A respeito ver também FELIPE, Sônia; PHILIPI, Jeanine Nicolazi. O corpo violentado: estupro e atentado violento ao pudor. Florianópolis: Gráfica/UFSC, 1996.
} 
texto legal."31

Desta forma, o julgamento de um crime sexual - inclusive e especialmente o estupro não é uma arena onde se procede ao reconhecimento de uma violência e violação contra a liberdade sexual feminina nem tampouco onde se julga um homem pelo seu ato. Trata-se de uma arena onde se julgam simultaneamente, confrontados numa fortíssima correlação de forças, a pessoa do autor e da vítima: o seu comportamento, a sua vida pregressa. E onde está em jogo, para a mulher, a sua inteira "reputação sexual" que é ao lado do status familiar - uma variável tão decisiva para o reconhecimento da vitimação sexual feminina quanto a variável status social o é para a criminalização masculina.

Regra geral, o conjunto probatório nos processos de estupro é extremamente frágil, limitando-se à prova pericial e testemunhal ou esgotando-se, muitas vezes, no depoimento da vítima. Isto é facilmente compreensível pelas circunstâncias em que ocorrem. São crimes geralmente praticados em lugares ermos ou na intimidade dos lares, distante do público e de testemunhas, sendo as partes envolvidas, muitas vezes, as únicas presentes. Esta é a razão, justifica-se, pela qual, nos crimes sexuais, a palavra da vítima e o laudo de exame de conjunção carnal assumem especial relevância, o que, aliás, parece unanimidade em matéria judicial, doutrinária e jurisprudencial Mas se exige, contudo, que sua palavra seja corroborada pelos demais elementos probatórios constantes dos autos, conforme o ilustram fragmentos do discurso decisório pesquisado. $^{32}$

\footnotetext{
${ }^{31}$. ARDAILLON, Danielle, DEBERT, Guita Grin. Quando a vítima é mulher. Análise de julgamentos de crimes de estupro, espancamento e homicídio. Brasília: Conselho Nacional dos Direitos da Mulher/ Ministério da Justiça, 1987, p.35

32. Decisões reiteradas dos tribunais brasileiros neste sentido (como RT 327/100, 387/301, 419/88, 498/292 e 533/376) podem ser ilustradas pelas ementas que seguem:

"Nos crimes contra os costumes, via de regra, a prova não é coetânea dos fatos, quase sempre sendo mais circunstancial que direta. Assim, a palavra da vítima é do maior valor probante, especialmente quando se trata de mulher recatada, sem aparente interesse em prejudicar o indigitado autor do delito."

"Diante de um passado tão comprometedor, conclui-se que as declarações da vítima não merecem fé, pois não estão corroboradas por outros elementos de prova...Por issso é que se afirma que a veracidade da negativa do denunciado quanto à prática do crime de estupro, sustentada desde a lavratura do auto de prisão em flagrantes, tem que prevalecer porque a palavra da vítima está despida do menor prestígio. “

"Tratando-se de mulher leviana, cumpre apreciar com redobrados cuidados a prova da violência moral. Tratando-se de vítima honesta, e de bons costumes, suas declarações tem relevante valor." "Se a vítima é leviana, a prova deve ser apreciada com redobrado cuidado." "A palavra da moça seduzida constitui prova de autoria do crime quando ela é honesta e de bons costumes e procedimento." "Se a mulher alega, sem qualquer lesão, ter sido estuprada por um só homem, que se utilizou da força física, suas declarações devem ser recebidas com reservas ou desconfiança". A respeito ver MIRABETTE, Julio Fabbrini. Manual de direito penal: parte especial. São Paulo: Atlas. 1986, v.3.p.408 e 420 e DELMANTO, Celso. Código Penal comentado. Rio de Janeiro: Renovar, 1988, p. 390.
} 
O que se pode perceber, pelo discursos analisados, é que estes "outros elementos probatórios" nada mais são do que a vida pregressa da própria vítima. Ora, se o conjunto probatório se reduz, muitas vezes, à própria palavra da vítima, então está a se exigir que sua palavra seja corroborada..... por sua vida pregressa, por sua moral sexual ilibada, por seu recato e pudor. Existindo ou não laudo pericial, ou ainda prova testemunhal, mesmo em situações de flagrante delito, a palavra da vítima perde credibilidade se não for ela considerada "mulher honesta", de acordo com a moral sexual patriarcal ainda vigente no SJC. O que vale, igualmente, para as vítimas mulheres que não são maiores de 14 anos, que tem a seu favor a presunção de violência (violência ficta) prevista do artigo 224, “a”, do CPB , mas que é sempre relativizada, pois somente vale ( lembre-se o célebre julgado do Ministro do STF, Marco Aurélio da Silveira) se a vítima for considerada honesta.

Ao tempo em que a vítima é julgada pela sua reputação sexual, é o resultado deste julgamento que determina a importância de suas afirmações.

Tais são as motivações latentes e reais da sentença que, integrando o senso comum judicial, decisivamente as condicionam, funcionando como mecanismos de seleção que, todavia, não se revelam como tais na sua fundamentação formal ( onde aparece a técnica juíridica com seus conceitos dogmáticos).

E não é diferente em relação às vítimas crianças, cuja palavra goza da mesma falta de credibilidade, embora por outro motivo: não são escutadas, não tem voz, porque a tendência é não se acreditar no que dizem ou se desqualificar a sua versão dos fatos como fantasias infantis.

O que ocorre, pois, é que no campo da moral sexual o sistema penal promove, talvez mais do que em qualquer outro, uma inversão de papéis e do ônus da prova. A vítima que acessa o sistema requerendo o julgamento de uma conduta definida como crime - a ação, regra geral é de iniciativa privada - acaba por ver-se ela própria "julgada" (pela visão masculina da lei, da polícia e da Justiça) incumbindo-lhe provar que é uma vítima real e não simulada.

Tem sido reiteradamente posto de relevo como as demandas femininas são submetidas a um intensa "hermenêutica da suspeita", do constrangimento e da humilhação ao longo do inquérito policial e do processo penal que vasculha a moralidade da vítima (para ver se é ou não uma vítima apropriada), sua resistência (para ver se é ou não uma vítima 
inocente), reticente a condenar somente pelo exclusivo testemunho da mulher (dúvidas acerca da sua credibilidade)

Em suma, as mulheres estereotipadas como desonestas do ponto de vista da moral sexual, inclusive as menores e, em especial as prostitutas, não apenas não são consideradas vítimas, mas podem ser convertidas, com o auxílio das teses vitimológicas mais conservadoras, de vítima em acusadas ou rés num nível crescente de argumentação que inclui ela ter "consentido", "gostado" ou "tido prazer", "provocado", forjado o estupro ou "estuprado" o pretenso estuprador. Especialmente se o autor não corresponder ao estereótipo de estuprador. Pois, correspondê-lo, é condição fundamental para a condenação.

Por isto mesmo a referência à Vitimologia e à pessoa da vítima relacionadamente à pessoa do autor, que não se dá com a mesma intensidade em todos os processos de criminalização, encontra nos crimes sexuais o lugar por excelência de sua utilização. É o que vimos, explicitamente declarado, na Exposição de Motivos do Código Penal Brasileiro de 1940, ao justificar a expressão "comportamento da vítima" introduzida no artigo 59 do Código Penal Brasileiro pela reforma penal de 1984: "Fez-se referência expressa ao comportamento da vítima erigida, muitas vezes, em fator criminógeno, por constituir-se em provocação ou estímulo à conduta criminosa, como, entre outras modalidades, o pouco recato da vítima nos crimes contra os costumes."

Nesta perspectiva, o senso comum policial e judicial não difere, uma vez mais, do senso comum social. O SJC distribui a vitimação sexual feminina com o mesmo critério que a sociedade distribui a honra e a reputação feminina: a conduta sexual. ${ }^{33}$

\section{2) Impunidade Imunidade e seleção de estupradores: da violência sexual à violência doméstica}

Isto nos conduz ao problema, tão caro ao feminismo, da impunidade: é que ser considerada vítima, nos labirintos da honestidade, não implica diretamente em punibilidade do autor.O SJC, que promete proteger as vítimas de crimes sexuais, absolve, ao que tudo indica, com muito maior freqüência do que condena. A regra, na conduta de estupro - seguindo a lógica do sistema - é a impunidade, e a condenação em casos limites, permanecendo contudo aquém da imunidade, pois, seguindo também a

\footnotetext{
33 . LARRAURI, Elena (Comp.). Mujeres, derecho penal y Criminologia. In: Control formal y el derecho penal de las mujeres. Contexto. Madrid: Siglo Veintiuno, 1994b,p.102.
} 
lógica de funcionamento do sistema, subsiste uma enorme cifra oculta da violência sexual, especialmente a doméstica, mesmo após toda a publicização e politização do problema pelo feminismo, e a criação das Casas e Delegacias de Mulheres.

Mas, quem pratica estupro e permanece no campo da imunidade/impunidade?E quem é efetivamente selecionado, rotulado ou etiquetado com o status negativo de estuprador? A indagação remete, por sua vez, à questão da autoria e etiologia do estupro, espaços e relações em que ocorre. Quanto à autoria, sabe-se hoje que os crimes sexuais são condutas majoritárias e ubíquas e não de uma minoria anormal, conforme preconiza o discurso jurídico-penal e criminológico oficial e o senso comum.Paulatinamente foi se descobrindo que o estupro ocorre com muito mais freqüência do que se imaginava, que cada homem pode ser o autor, que cada mulher pode ser a vítima e que a vítima e o autor muito freqüentemente se conhecem. Tratam-se de violências praticadas por estranhos, na rua, sim. Mas sobretudo, e majoritariamente, nas relações de parentesco (por pais, padrastos, maridos ,primos), profissionais (pelos chefes) e de conhecimento em geral ( amigos). Ocorrem, portanto, na rua, no lar e no trabalho, contra crianças, adolescentes, adultas e velhas, tendo sido denunciado contra vítimas desde poucos meses de idade até sexa ou octosagenárias e praticadas por homens que nada tem de tarados, desviados sexuais ou anormais, mas um vínculo forte com a vítima. Violência sexual é, em grande medida, violência doméstica: paradoxalmente a família, que deveria ser um espaço de proteção, é também - como o SJC - um espaço de violência e violação.

Quanto a etiologia do estupro, argumenta-se, na esteira da primeira argumentação, que não se trata de conduta voltada, prioritariamente, para a satisfação do prazer sexual( lascívia desenfreada), como também preconiza o discurso criminológico e jurídicopenal oficial e o senso comum. A pesquisa de Kolodny, Masters e Johnson ${ }^{34}$ conclui, neste sentido, que " a maioria dos estupros ocorrem dentro de um contexto de violência física em vez de paixão sexual ou como meio para a satisfação sexual. Pois, prosseguem, "constatamos que ou a força ou a ira dominam, e que o estupro, em vez de ser principalmente uma expressão de desejo sexual, constitui, de fato, o uso da sexualidade para expressar questões de poder e ira. O estupro, então, é um ato pseudosexual, um padrão de comportamento sexual que se ocupa muito mais com o status,

34 . KOLODNY, Robert. C., MASTERS, William H, JOHNSON, Virginia E. Manual de medicina sexual. Tradução por Nelson Gomes de Oliveira. São Paulo: Manole, 1982. p.430-431 
agressão, controle e domínio do que com o prazer sexual ou a satisfação sexual. Ele é comportamento sexual a serviços de necessidades não sexuais."

As mulheres começaram a dar-se conta de que o estupro ( assim como os maus-tratos, o incesto, a prostituição, o assédio sexual no trabalho etc.)são também produtos de uma estrutura de poder, a existente entre homens e mulheres e o argumento da violência individual foi cedendo espaço ao argumento da violência estrutural. ${ }^{35}$

O conjunto das conclusões criminológicas críticas e feministas é por demais significativa: se o espaço privado-familiar é um locus de incidência majoritária da violência sexual (e seus integrantes os sujeitos centrais envolvidos) pode-se interpretar que isto sucede - para além dos elementos intersubjetivos implicados nas relações de violência - porque, historicamente, na sociedade patriarcal, a família tem sido um dos lugares nobres, embora não exclusivo ( porque acompanhada da Escola, da Igreja, da vizinhança, etc), precisamente do controle social informal sobre a mulher. E a violência contra a fêmea no lar, do pai ao padastro, chegando aos maridos ou companheiros, pode ser vista, portanto, ( contrariamente à ideologia do agressor como expressão de uma aberração sexual e da busca do gozo) como uma expressão de poder e domínio; como uma violência controladora.E, num sentido último, como pena privada.

A violência aparece como o elemento masculino comum, presente no poder punitivo do Estado sob a forma de pena pública e no poder punitivo da família ( Pais, padrastos, maridos, companheiros) sob a forma de pena privada, e age nas duas esferas como a última garantia de controle, embora o estilo dos dois sistemas seja diferente.

Embora, contudo, já cientificamente desfeita a mitologia que circunda o estupro, tanto na autoria, relações e espaços, quanto na etiologia, continua-se reproduzindo o estereótipo do estuprador como um ser anormal, de lascívia desenfreada, estranho à vítima (e, numa preconceituação masculina, continua-se acentuando o encontro sexual e o coito vaginal antes que a violência. E este estereótipo continua agindo no SJC, condicionando tanto a seleção quanto a impunidade, pois embora domine a violência familiar e entre conhecidos, a seleção se dá fora dela: os etiquetados como estupradores, ao que tudo indica, são estranhos à vítima e, regularmente, pertencentes aos baixos

35 .BEIJERSE, Jolande Uit, KOOL, Renée. ¿La tentación del sistema penal: apariencias enagañosas? El movimiento de mujeres holandés, la violencia contra las mujeres y el sistema penal. In: LARRAURI, Elena (Comp.) Mujeres, derecho penal e Criminologia. Madrid: Siglo Veintiuno, 1994.p.143. 
estratos sociais..

O estupro é, pois, uma conduta majoritária e ubíqua, mas desigualmente distribuída, de acordo, sobretudo, com estereótipos de estupradores que operam em nível do controle social formal e informal .

É mais fácil etiquetar como estupro a conduta cometida por um estranho na rua, que a realizada pelo chefe ou pelo marido, cuja possibilidade está, em algumas legislações ou jurisprudências, explicitamente excluída. ${ }^{36}$ Ora, os familiares (maridos, padrastos, primos), colegas e amigos, não correspondem, em absoluto, ao estereótipo de estupradores. Por outro lado, nada é tão forte dentro do estereótipo de criminoso quanto o subestereótipo de estuprador

\section{3) A proteção da família patriarcal/capitalista: $O$ continuum entre controle penal e familiar, ente pena pública e privada ${ }^{37}$}

Num plano mais profundo, pois, chega-se a uma importante conclusão sobre o objeto jurídico latentemente protegido através da sublógica da honestidade. ( a qual, como a seletividade revela-se como marca estrutural do exercício de poder do sistema penal) O SJC não protege, em absoluto, a liberdade sexual feminina (que, por isso mesmo, é pervertida ( a mulher que diz não quer dizer talvez; a que diz talvez quer dizer sm.e a que diz não é, em absoluto, uma mulher ). O SJC é ineficaz para proteger o livre exercício da sexualidade feminina e o domínio do próprio corpo. Se assim o fosse , todas as vítimas seriam consideradas iguais perante a lei e o assento seria antes no fato crime e na violência do que na conjunção carnal. E teriam do sistema o reconhecimento e a solidariedade para com a sua dor. Não é casual que ocorra o inverso.

A sexualidade feminina referida ao coito vaginal diz respeito à reprodução. E a função reprodutora (dentro do casamento) se encontra protegida sob a forma da sexualidade honesta, que é precisamente a sexualidade monogâmica (da mulher comprometida com o casamento, a constituição da família e a reprodução legítima), de modo que

\footnotetext{
${ }^{36}$. O referido artigo 213 do Código Penal Brasileiro não proíbe, com efeito, que o marido possa ser sujeito ativo de estupro contra a esposa. Mas na doutrina e jurisprudência goza de forte tradição e hegemonia a tese que sustenta a impossibilidade, sob o argumento de que um dos deveres do casamento civil é a prestação carnal, e a mulher não pode, portanto, recusá-la.

37 . Daí, também, o rigor da criminalizacão de lenocínio ( crimes de favorecimento à prostituição, rufianismo etc. ) nada viola tanto a família patriarcal quanto o estupro, de um lado, e a prostituição, por outro, pois ao profanar a monogamia,os vários leitos ferem a linhagem sucessória masculina
} 
protegendo-a, mediante a proteção seletiva da mulher honesta, se protege, latente e diretamente a unidade familiar e, indiretamente, a unidade sucessória (o direito de família e sucessões) que, em última instância, mantém a unidade da própria classe burguesa no capitalismo.

A proteção é, em nível micro, da moral sexual dominante e da família (unidade familiar e sucessória segundo o modelo da família patriacal/capitalista monogâmica, heterossexual, destinada à procriação legítima, etc; ainda que este modelo esteja passando hoje por profundas transformações culturais e jurídicas.

Em nível macro, a função real do sistema é manter estruturas, instituições e simbolismos, razão pela qual, repita-se, não pode ser um aliado no fortalecimento da autonomia feminina Nesta esteira, "Também fica claro o papel da família como mediadora entre o sistema patriarcal e a sociedade de classes; e tomando em consideração que o sistema patriarcal é mais antigo do que o sistema de classes, pode-se afirmar que está por baixo do sistema capitalista. Assim, a família tem importante função dupla: ser a mediadora entre o indivíduo e a classe social, e entre o sistema capitalista e a cultura patriarcal ( que lhe dá um valor muito mais alto do que se pensava numa ciência social centrada no homem $)^{38}$

Chegado a este ponto pode-se melhor compreender e ressignificar o problema da impunidade. Traduzido nos termos criminológicos aqui desenvolvidos, o tratamento que o sistema de justiça criminal confere à violência sexual, particularmente ao estupro, pode ser formulado na promessa de punir com pena pública o autor da pena privada, o que implica o deslocamento do controle masculino individual (homens em geral, pais, padrastos, maridos) para o controle masculino institucional ( Estado-homens).

Mas, em definitivo, não há esta punição . A pena, que deveria não só simbolizar, mas materializar a proteção, não incide e na forma de impunidade-imunidade reafirma-se o continuum profundo entre o controle familiar e o penal e a solidariedade masculina destes controles. A impunidade é a cumplicidade ou solidariedade masculina do SJC para com a família patriarcal.$^{39}$ Não existe uma instância que faça a assepsia, todas se

${ }^{38}$. MURARO, Rose Marie. Textos da Fogueira.Brasília,:Letraviva, 2000, p.142:

39. A respeito, ver também FELIPE, Sônia; PHILIPI, Jeanine Nicolazi. O corpo violentado: estupro e 
contaminam.A tentativa histórica- todavia frustrada- foi, como vimos, da Ciência penal.

\section{7)Retornando à dor e concedendo a voz aos sujeitos}

Se ao longo de minha fala enfatizei que o que sustenta o sistema de justiça criminal é, a um só tempo, a força das estruturas e das ideologias, e que nesta dimensão ( simbólica) o SJC ( assim como os criminosos e as vítimas) somos todos nós, e o tratamento que confere à mulher é o mesmo que o público-senso comum lhe confere (incluindo as famílias, os maridos, os chefes,os homens e, inclusive, as mulheres), somente posso concluir que o limite do sistema é, em nível macro, o limite da própria sociedade e, em nível micro, o limite das instituições e dos sujeitos: é o nosso próprio limite . Não existem modelos, oficiais ou outros, que não arrastem consigo as marcas destes limites.

Assim sendo,parece haver um duplo caminho a indicar e duas palavras chaves: inclusão e co-responsabilização; ou melhor, uma dupla inclusão do que parece ser o Outro (alter -outsiders): a) a nossa inclusão e co-responsabilização, estrutural, na mecânica da violência ( e na sua superação) e b) a inclusão de homens e mulheres , como sujeitos, nas relações de violência, e sua percepção, para além de estrutural e institucional, como relacional ( intersubjetiva), o que implica conceder voz a todos os sujeitos envolvidos e à sua dor, iniciando por problematizar a grande rubrica unilateral do feminismo: violência contra a mulher. A ultrapassagem das lógicas da seletividade e da honestidade ( violência institucional que expressa violência estrutural), bem como da violência sexual é, portanto, um desafio individual e coletivo, micro e macro, profundo, num tempo de expressivas transformações nas relações sexuais e de gênero, e no qual não mais se legitimam, nem "desigualdades inferiorizadoras", nem "igualdades descaracterizadoras".

Artigo publicado na: Revista Brasileira de Ciências Criminais. São Paulo: Revista dos Tribunais, n.48, maio-jun. 2004. p. 260-290

Justiça e Direito: Revista Sequiência. Florianópolis: Boiteux, ano XXV, n.50, jul./2005,p.71-102.

Revista Sequiência de Pós-Graduação em Ciências Jurídicas do UniCEUMA.São Luis, v.1, n.1, jul./dez. 2004.

atentado violento ao pudor. Florianópolis: Gráfica/UFSC, 1996, p. 18 : “ No estudo da violência sexual, cuidamos de tornar explícitas a responsabilidade e a cumplicidade da sociedade com relação ao modo como normalmente a vitima da violéncia e tratada. (...)Nosso trabalho critica explicitamente uma espécie de solidariedade para como o violentador e de culpabilizacao da vitima de atentados sexuais, típica de nossa cultura." 
Texto apresentado no painel "O Sistema de Justiça criminal no tratamento da violência contra a mulher “, no $9^{\circ}$ Seminário Internacional do IBCCrim. 